\title{
Comparison of Two Headgear Systems for Sleep Apnea Treatment of Stroke Patients
}

\author{
Devin L. Brown ${ }^{\mathrm{a}}$ Maryann Concannon ${ }^{\mathrm{a}}$ Aaron B. Kaye ${ }^{\mathrm{a}}$ Michael Zupancic $^{\mathrm{c}}$ \\ Lynda D. Lisabeth ${ }^{\mathrm{a}, \mathrm{b}}$ \\ aStroke Program, University of Michigan Medical School, and bepartment of Epidemiology, University of \\ Michigan School of Public Health, University of Michigan, Ann Arbor, Mich., and 'Pacific Sleep Medicine Services, \\ San Diego, Calif., USA
}

\section{Key Words}

Sleep apnea, obstructive $\cdot$ Stroke patients $\cdot$ Continuous positive airway pressure masks $\cdot$ Patient satisfaction

\begin{abstract}
Background: Obstructive sleep apnea is a very common condition after stroke, and it predicts poor outcomes. Unfortunately, stroke patients often do not tolerate continuous positive airway pressure. We hypothesized that a 1-piece head frame headgear would be easier and quicker to use than a traditional strap headgear. Methods: A convenience sample of ischemic stroke patients was taught to use 2 different headgear systems, a head frame and straps. Subjects were timed while putting on and taking off the 2 headgears, and they were queried about their ease of use. Results: All the 30 enrolled subjects found the head frame to be easier to apply and to remove than the straps. The patients took longer to put on $(p<0.01)$ and to remove $(p<0.01)$ the straps than the head frame. Conclusions: Headgear selection should be considered when fitting a stroke patient with a continuous positive airway pressure mask.
\end{abstract}

Copyright ๑ 2008 S. Karger AG, Basel

\section{KARGER}

Fax +4161306 1234 E-Mail karger@karger.ch www.karger.com (c) 2008 S. Karger AG, Base

Accessible online at: www.karger.com/ced
Obstructive sleep apnea (OSA) is very common in ischemic stroke patients, with a prevalence of more than $50 \%$ [1]. OSA has been shown to be associated with poor outcome after a stroke, including functional outcome and mortality [2-4], suggesting the importance of OSA treatment in this population. Unfortunately, the tolerance of stroke patients to continuous positive airway pressure (CPAP) is poor [5]. Little is known about improving compliance to CPAP for stroke patients. Because of their deficits, including visual, attention, cognitive, motor and sensory impairments, there are unique issues related to applying and removing CPAP masks in this population.

There are numerous types of CPAP headgear systems and mask interfaces. Differences in the complexity of application and removal of the various headgears exist. For instance, some configurations of headgear systems are more amenable to a 1-handed application than others. We sought to compare the ease and speed of application and removal of 2 different CPAP headgear systems in patients with stroke: Respironics' Premium Headgear and Puritan Bennett's Breeze ${ }^{\circledR}$ Sleep Gear ${ }^{\circledR}$. We hypothesized that the 1-piece head frame headgear would be easier to use and more quickly applied and removed than the straps.
Devin L. Brown, MD

The Cardiovascular Center - Stroke Program

1500 E. Medical Center Drive - SPC No. 5855

Ann Arbor, MI 48109-5855 (USA)

Tel. +1 734936 9075, Fax +1 734232 4447, E-Mail devinb@umich.edu 


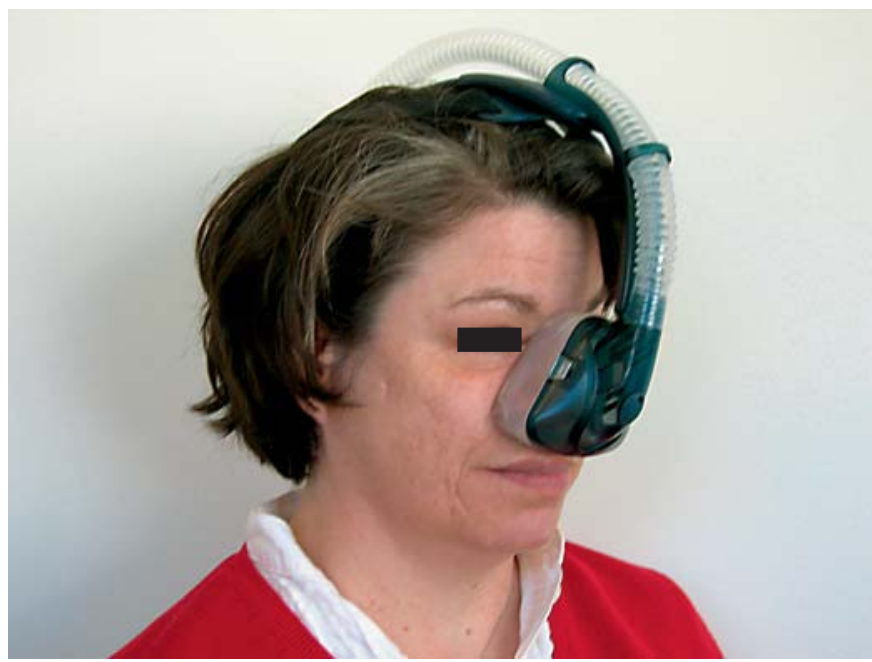

Fig. 1. Head frame.

\section{Methods}

\section{Study Design}

The study was approved by the University of Michigan's Institutional Review Board. Patients hospitalized at the University of Michigan for ischemic stroke, defined by clinical criteria [6], were offered participation in the study between May 2007 and March 2008. The patients were excluded if they were unable to provide consent, or if they had had prior exposure to CPAP. The target enrollment was 30 patients. Demographic and clinical information was obtained from the medical record. Self-reported height and weight were documented. The modified Rankin scale was administered at the time of enrollment. Disability was defined by a score of 2 or more. Two different mask/headgear set-ups were tried: Puritan Bennett's Breeze Sleep Gear with Dream Seal standard size nasal mask ('head frame'; fig. 1), and Respironics' Premium Headgear with the appropriate size comfort gel nasal mask ('straps'; fig. 2). These were selected as representative of traditional strap headgears and nontraditional 1-piece headgear units. $\mathrm{Na}$ sal masks were used for both set-ups to minimize differences aside from the headgear. The Breeze Sleep Gear Nasal Interface System is a 1-piece unit that fits over the head. It consists of a padded cradle, a spine with a connecting metal brace and halo straps laced through the outrigger plastic flange. The Premium Headgear is a 'one-size-fits-most' headgear made of lycra straps. The system can be removed by unhooking and secured by reattaching a single ball-and-socket headgear attachment, thereby maintaining the headgear adjustment. The order by which the systems were presented was based on blocked randomization.

\section{Procedures}

The straps were assembled for the patients, with the exception of a single ball-and-socket headgear attachment. The head frame was also assembled with the halo straps. The first system was applied and adjusted to the patient by a certified sleep technologist, and the technique was taught to the patient. The patient then practiced putting on the mask and tested out the comfort while

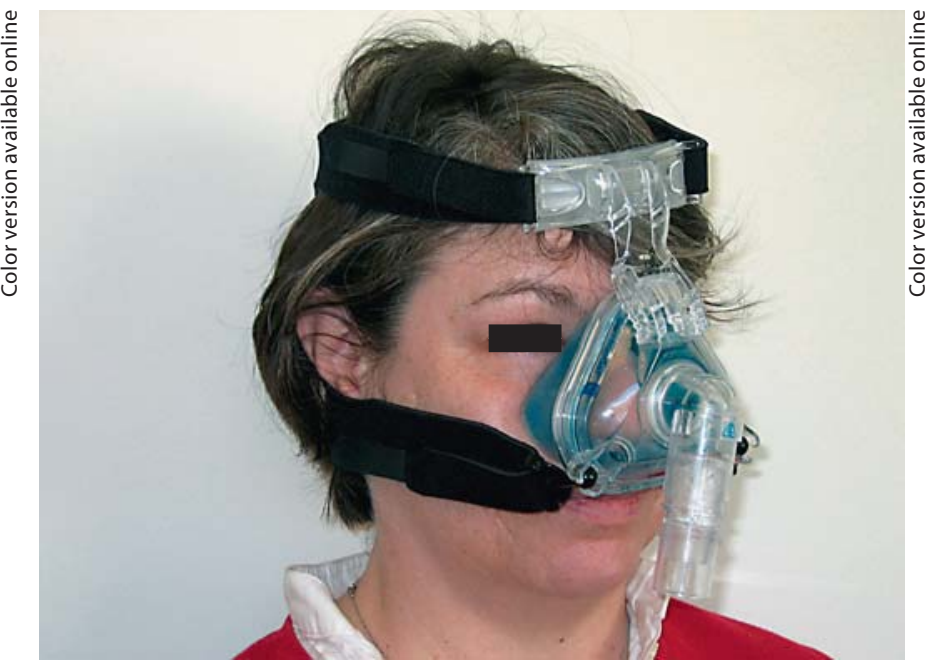

Fig. 2. Straps.

supine in bed. The subject was encouraged to turn his/her head in bed. The system was then removed. Afterwards, the subject put on and removed the first headgear system while being timed. The process was repeated for the second headgear system. A questionnaire was then administered to the patient. This questionnaire compared the perceived ease of use, comfort and the overall preference of the 2 systems measured on a Likert scale: definitely head frame, probably head frame, uncertain, probably straps, definitely straps.

\section{Statistical Methods}

The frequencies and percentages were calculated for demographic and clinical characteristics. The medians with interquartile ranges (IQR) were calculated for the continuous variables. The two-sample paired Wilcoxon signed-rank tests were used to compare the objective time required to put on and to remove the 2 headgear systems. To be conservative, a missing value was substituted if the subject was unable to apply or to remove 1 of the headgear systems. Analyses were performed for all subjects and repeated on the subset of those patients who had some disability based on the modified Rankin scale score.

\section{Results}

Thirty subjects were enrolled; their median age was 62 years (IQR: 54, 72). Thirteen (43\%) were male. The median body mass index was 27 (IQR: 24, 30). The majority (74\%) had at least some disability based on the modified Rankin scale, with 19 (63\%) having a motor, coordination or neglect deficit involving the arm. The modified Rankin scale score distribution was as follows: 0,1 patient $(3 \%)$; 1,7 patients $(23 \%) ; 2,5$ patients $(17 \%) ; 3,8$ patients $(27 \%)$; 4,9 patients $(30 \%)$. 
Table 1. Subjective report of ease, comfort and preference of headgear systems: all subjects $(\mathrm{n}=30)$

\begin{tabular}{lllllr}
\hline & $\begin{array}{l}\text { Definitely } \\
\text { head frame }\end{array}$ & $\begin{array}{l}\text { Probably } \\
\text { head frame }\end{array}$ & $\begin{array}{l}\text { No } \\
\text { preference }\end{array}$ & $\begin{array}{l}\text { Probably } \\
\text { straps }\end{array}$ & $\begin{array}{l}\text { Definitely } \\
\text { straps }\end{array}$ \\
\hline $\begin{array}{l}\text { Easiest to put on and take off } \\
\text { More comfortable }\end{array}$ & $29(97 \%)$ & $1(3 \%)$ & - & - & - \\
Overall preference & $13(43 \%)$ & - & - & $5(17 \%)$ & $12(40 \%)$ \\
$8(27 \%)$
\end{tabular}

Table 2. Subjective report of ease, comfort and preference of headgear systems: subjects with disability $(n=22)$

\begin{tabular}{llllll}
\hline & $\begin{array}{l}\text { Definitely } \\
\text { head frame }\end{array}$ & $\begin{array}{l}\text { Probably } \\
\text { head frame }\end{array}$ & $\begin{array}{l}\text { No } \\
\text { preference }\end{array}$ & $\begin{array}{l}\text { Probably } \\
\text { straps }\end{array}$ & $\begin{array}{l}\text { Definitely } \\
\text { straps }\end{array}$ \\
\hline $\begin{array}{l}\text { Easiest to put on and take off } \\
\text { More comfortable }\end{array}$ & $21(95 \%)$ & $1(5 \%)$ & - & - & - \\
Overall preference & $10(45 \%)$ & - & - & $3(14 \%)$ & $9(41 \%)$ \\
& $13(59 \%)$ & - & - & $4(18 \%)$ & $5(23 \%)$ \\
\hline
\end{tabular}

Almost all subjects found the head frame system to be easier to apply and to remove, while subjective comfort and an overall sense of preference were more evenly divided between the 2 headgear systems (table 1). When limiting the assessment to only those patients with disability $(\mathrm{n}=22)$, the results were similar (table 2$)$. The patients took longer to put on $(\mathrm{p}<0.01)$ and to remove $(\mathrm{p}<$ $0.01)$ the straps than the head frame. All subjects were able to put on and to take off the head frame. The median time for applying the head frame was $10 \mathrm{~s}$ (IQR: 6, 14). Removing the head frame took a median of $3 \mathrm{~s}$ (IQR: 2, 4). Eleven (37\%) of the subjects could not put on the strap headgear; while 3 of them (10\%) could not remove it. Among those who were able to put on and remove the strap headgear, the median time to apply the straps was 110 s (IQR: 54, 151). The median time to remove the straps was 8 s (IQR: 4,13$)$. The median times were unchanged in those subjects with disability.

\section{Discussion}

In this convenience sample of mostly disabled, hospitalized ischemic stroke patients, the vast majority found it easier and they were more quickly able to put on the head frame headgear system than the straps. All subjects were able to put on and take off the head frame, while a sizable proportion (37\%) was unable to put on the strap system. These results underscore the importance of working with stroke patients to select not only the mask, but also a headgear system that is workable, given the patients' deficits. The discordance between the subjective ease of use and the overall preference further suggests the need to query patients about their preferences.

Numerous studies have compared various CPAP interfaces, such as nasal pillows, nasal and oral masks [7], but very little attention has been paid to CPAP headgear. Those studies that have demonstrated poor CPAP compliance in stroke patients have not described the headgear system used, or attempts made to individualize the selection of the headgear [5, 8-11]. Although there are no data available on how headgear systems relate to CPAP adherence in stroke patients, it would stand to reason that not being able to use a headgear system on his/her own would limit CPAP usage. After all, difficulty in applying a headgear has been identified as one of the factors which impairs the acceptance of CPAP in stroke patients [5]. Facilitating the headgear removal by the use of a 1-piece head frame may reduce concerns about the inability to remove the CPAP mask in the middle of the night.

Currently, there are no randomized, controlled trial data supporting the cerebrovascular benefits of CPAP for stroke patients with sleep apnea. However, there are observational studies showing that compliance with CPAP is associated with a lower risk of cardiovascular and cerebrovascular events and death [11-13]. If this association is proven to be causally related to CPAP use, ways to improve CPAP adherence in stroke patients will become even more important. 
There are some limitations to this study. We did not limit the participants to those with OSA only. Presumably, the neurological impairments that influence the ease of CPAP headgear use in stroke patients with and without OSA are similar. We did not compare the compliance to CPAP by using the 2 different headgear systems, but rather focused on the ease and speed of the mask application and its removal. It is possible that the comfort experienced with the head frame headgear was diminished by the use of a hospital pillow, which has a thermoplastic cover. The cradle portion of the head frame may seem less comfortable when rested on this surface than on a traditional home use pillow. The study was based on a small convenience sample of ischemic stroke patients from an academic medical center, so the findings may not be generalizable to a broader population of stroke patients.

This study suggests that headgear selection may be an important contributor to a stroke patient's ability to use CPAP without any assistance. Future studies assessing CPAP for stroke patients should consider to individualize the selection of a headgear for study subjects.

\section{Acknowledgements}

Dr. Lisabeth is supported by a NINDS career development award (K23 NS050161); Dr. Brown is supported by a NINDS career development award (K23 NS051202). The study was funded by NINDS K23 NS051202. Respironics Inc. and Puritan Bennett provided material support.

\section{References}

1 Bassetti C, Aldrich M: Sleep apnea in acute cerebrovascular diseases: final report on 128 patients. Sleep 1999;22:217-223.

$\checkmark 2$ Good D, Henkle J, Gelber D, Welsh J, Verhulst S: Sleep-disordered breathing and poor functional outcome after stroke. Stroke 1996;27:252-259.

-3 Sahlin C, Sandberg O, Gustafson Y, Bucht G, Carlberg B, Stenlund H, Franklin KA: Obstructive sleep apnea is a risk factor for death in patients with stroke: a 10-year follow-up. Arch Intern Med 2008;168:297-301.

4 Turkington PM, Allgar V, Bamford J, Wanklyn P, Elliott MW: Effect of upper airway obstruction in acute stroke on functional outcome at 6 months. Thorax 2004;59:367-371.

5 Palombini L, Guilleminault C: Stroke and treatment with nasal CPAP. Eur J Neurol 2006;13:198-200.
6 Asplund K, Tuomilehto J, Stegmayr B, Wester PO, Tunstall-Pedoe H: Diagnostic criteria and quality control of the registration of stroke events in the MONICA project. Acta Med Scand Suppl 1988;728:26-39.

7 Chai CL, Pathinathan A, Smith B: Continuous positive airway pressure delivery interfaces for obstructive sleep apnoea. Cochrane Database Syst Rev 2006;4:CD005308.

-8 Bassetti CL, Milanova M, Gugger M: Sleepdisordered breathing and acute ischemic stroke: diagnosis, risk factors, treatment, evolution and long-term clinical outcome. Stroke 2006;37:967-972.

$\checkmark 9$ Broadley SA, Jorgensen L, Cheek A, Salonikis S, Taylor J, Thompson PD, Antic R: early investigation and treatment of obstructive sleep apnoea after acute stroke. J Clin Neurosci 2007;14:328-333.
10 Hsu CY, Vennelle M, Li HY, Engleman HM, Dennis MS, Douglas NJ: Sleep-disordered breathing after stroke. A randomized controlled trial of continuous positive airway pressure. J Neurol Neurosurg Psychiatry 2006;77:1143-1149.

11 Martinez-Garcia MA, Galiano-Blancart R, Roman-Sanchez P, Soler-Cataluna JJ, Cabero-Salt L, Salcedo-Maiques E: Continuous positive airway pressure treatment in sleep apnea prevents new vascular events after ischemic stroke. Chest 2005;128:2123-2129.

12 Marin JM, Carrizo SJ, Vicente E, Agusti AG: Long-term cardiovascular outcomes in men with obstructive sleep apnoea-hypopnoea with or without treatment with continuous positive airway pressure: an observational study. Lancet 2005;365:1046-1053.

13 Doherty LS, Kiely JL, Swan V, McNicholas WT: Long-term effects of nasal continuous positive airway pressure therapy on cardiovascular outcomes in sleep apnea syndrome. Chest 2005;127:2076-2084. 